\title{
SAÚDE E EDUCAÇÃO AMBIENTAL: UM RELATO DE CASO NO MUNICIPIO DE TEODORO SAMPAIO, SP.
}

\author{
Jaqueline Adelânia Sarti ${ }^{1}$
}

Leonice Seolin Dias ${ }^{2}$

\section{Jovelino José da Silva Junior ${ }^{3}$}

RESUMO: Este artigo apresenta o relato de experiência do trabalho desenvolvido entre universidade e poder público na área da saúde e da educação ambiental no município de Teodoro Sampaio. O objetivo do trabalho foi sensibilizar a comunidade escolar, em especial os alunos, acerca da importância dos cuidados com o meio ambiente para assegurar uma saúde pública mais saudável, evidenciando as correlações entre um (meio ambiente) e outro (saúde pública). Nesta parceria, a universidade, pautada por pesquisas cientificas, desenvolveu na Semana do Meio Ambiente um trabalho de sensibilização dos alunos acerca das implicações decorrentes das ações antrópicas no meio ambiente. O trabalho privilegiou as ações antrópicas que promovem a proliferação de agentes patogênicos, assim como as implicações dessa proliferação no que diz respeito à ocorrência de doenças no homem. No ambiente escolar foram desenvolvidas as atividades em conjunto com os educadores de forma que os alunos pudessem ser protagonistas do processo educativo por meio de atividades que Ihes permitissem relacionar conhecimentos de disciplinas e áreas distintas (biologia e geografia; saúde e educação ambiental), se situarem no seu contexto sócio-espacial e se expressarem artisticamente. Por fim avaliamos positivamente tal ação de sensibilização, a qual, integradas com outras,

\footnotetext{
${ }^{1}$ Enfermeira Especialista em Educação, Comunicação e Informação (IEC) na Equipe de Controle de Vetores de Teodoro Sampaio- SP ((jaqueline.sarti@hotmail.com)

2 Doutoranda em Geografia pela Universidade Estadual Paulista (UNESP) de Presidente Prudente,SP (nseolin@gmail.com)

${ }^{3}$ Geógrafo, coordenador da EMEF Pedro Caminoto do município de Teodoro Sampaio, SP jovelino_junior@yahoo.com.br
} 


\section{Periádica Eletránica \\ Fórum Ambiental \\ ISSN 1980-0827}

ANAP da Alta Paulista
Volume 8, Número 12, 2012

Saúde, Saneamento e

Meio Ambiente

contribui com o processo de conscientização ambiental e mudança de atitudes.

Palavras-chaves: Zoonoses. Vetores de doenças. Educação Ambiental.

\section{INTRODUÇÃO}

O presente trabalho trata de um relato de experiência sobre as atividades realizadas na Semana do Meio Ambiente, de 05 a 10 de junho de 2012, na E. E. Pedro Caminoto no município de Teodoro Sampaio, SP. As atividades foram elaboradas por Jaqueline Adelânia Sarti (Enfermeira na Educação, Informação e Comunicação (IEC) do Centro de Vigilância de Teodoro Sampaio); Jovelino José da Silva Junior (Professor e coordenador da E. M. E. F Pedro Caminoto), Maria Imaculada Souza dos Santos (Supervisora da Equipe de Controle de Vetores - ECV) e Leonice Seolin Dias (doutoranda em Geografia/Laboratório de Biogeografia e Geografia da Saúde da UNESP de Presidente Prudente, SP.

Para a realização de estudos na linha de pesquisa "Ambiente e Saúde", o CEMESPP possui o Laboratório de Biogeografia e Geografia da Saúde da UNESP/ Presidente Prudente, SP, que se interessa por problemas ligados à qualidade de vida e de questões diretamente relacionadas a aspectos como: poluição do ar, poluição da água, enchentes, resíduos sólidos, epidemias, etc.

A partir destas preocupações, o laboratório vem desenvolvendo pesquisas sobre a população de dípteros, uma vez que dentre os insetos que se adaptaram ao ambiente construído pelo homem destacam-se as moscas, pela sua diversidade de espécies, abundância populacional, o curto ciclo reprodutivo e a dificuldade de controle (SILVA, SEOLIN DIAS, GUIMARAES, 2011; SEOLIN DIAS, FONCESA, GUIMARAES, 2012; SEOLIN DIAS; GUIMARAES, 2009).

As atividades da Equipe de Controle de Vetores (ECV) do município de Teodoro Sampaio visam prevenir que os vetores da dengue, leishmaniose, escorpião, entre outros, se proliferem em larga escala e com isso tragam uma epidemia para o município. 
trabalho dos agentes é desenvolvido através de visitas casa a casa, realizadas diariamente, onde se busca, com auxílio de fichas de manejo entregue aos moradores, sanar as irregularidades encontradas. O profissional de Informação, Educação e Comunicação (IEC) fica responsável pelo desenvolvimento de ações educativas para a população em geral, buscando a conscientização populacional através da informação.

Os trabalhos realizados pela ECV contam com a participação de grandes parceiros: a Vigilância Sanitária Municipal, Departamento de Infraestrutura, Serviços Gerais e Projetos realizados com universidades para o desenvolvimento de atividades no ambiente escolar.

\section{Zoonoses, Saúde e Educação Ambiental}

No Brasil há ecossistemas com gigantesca biodiversidade de flora e fauna. Porém, é lamentável a ação do homem na destruição desses ecossistemas em larga escala, que pode trazer consequências desastrosas à vida na terra. $\mathrm{O}$ avanço da agricultura e da pecuária próximas às áreas naturais possibilitou contato entre as populações humanas e seus animais domésticos com as populações de animais silvestres nos seus habitats.

Esse estreito contato facilitou a disseminação de agentes infecciosos e parasitários para novos hospedeiros e ambientes, estabelecendo-se assim novas relações entre hospedeiros e parasitas. Como consequências dessas interações negativas podem ocorrer zoonoses com expansão epidêmica (SILVA, 2008). Entende-se que as zoonoses são doenças ou infecções comuns, naturalmente transmissíveis, entre os animais e o homem, segundo a World Health Organization (1967). As zoonoses se distribuem em níveis de ocorrências variáveis, de acordo com fatores ambientais físicoquímicos e biológicos, aliados a fatores socioeconômicos e culturais.

Em decorrência de sua importância, tanto do ponto de vista social, quanto do ponto de vista econômico, é necessária a adoção de medidas capazes de minimizar transtornos, através da aplicação de métodos adequados para a prevenção, controle ou erradicação dessas doenças (BRASIL, 2005; MIGUEL, 1996).

Segundo Lima et al. (2010) citando Comis et al. (2005): 
.... aumento da incidência destas doenças ocorre, geralmente, sob condições adversas de vida, que se atrelam a processos de degradação ambiental. A disseminação de muitas doenças ocorre com maior frequência em áreas populacionais de baixa renda, com má estrutura sanitária, onde o homem altera as condições naturais do meio e modifica as paisagens naturais. Dessa forma, os elos de ligação entre o homem e o meio em que vive tornam-se um fator de risco à saúde, pois os elementos ambientais e antrópicos são constantemente a base para a proliferação e desenvolvimento de agentes patogênicos.

Ainda, conforme Forattini (2004), o surgimento de ecossistemas artificiais, em função da ação antrópica, tem criado novos habitats, resultantes do processo de urbanização. Esses habitats passam a ser preenchidos por populações de espécies da fauna nativa, que anteriormente já habitavam estes ambientes, ou exótica, proveniente de outras regiões geográficas.

Por exemplo, algumas espécies de moscas da família Calliphoridae (moscas varejeiras) que foram introduzidas no Brasil na década 1970, foram rapidamente dispersas para todo o território nacional. Esses califorídeos e outras famílias de moscas sinantrópicas são encontrados em ambientes urbanos e rurais, e podem causar doenças ou atuarem como vetores mecânicos ou biológicos de organismos patogênicos. Segundo Zumpt (1965) e Greenberg (1971), são responsáveis pela transmissão de doenças veiculadas por bactérias, vírus, protozoários e helmintos, e podem causar miíases, conhecidas por bicheiras, tanto no homem como nos animais.

Além disso, para Carrera (1991):

... as moscas contaminadas estão sempre pousando livremente sobre objetos (fogão, mesas, pias, etc.), em que se encontram os alimentos, e, conseqüentemente, contaminando-os. Sua importância como veiculadora mecânica de agentes infecciosos de várias doenças é muito evidente, pelo fato das mesmas viverem no interior de residências, escolas, restaurantes e similares, após alimentarem-se de dejetos em ambientes insalubres. Além dos vômitos digeridos sobre os alimentos, podem, também, depositar sobre eles as suas fezes.

Constitui-se medida eficiente para redução do risco da proliferação dos vetores o seu combate por meio de ações de saneamento básico e de educação em saúde. Um aspecto relevante está na relação entre o homem e o animal, que se tornam cada vez 
mais próximos, pelo hábito de se criar em casa e apartamento "animais de estimação", como cães, gatos, aves ornamentais, hamsters, entre outros, que são fatores de risco.

Segundo Almeida Filho e Rouquayrol (2002), esse convívio próximo entre o homem e seus animais de estimação não fica limitado apenas a uma situação de coabitação familiar, já que esses animais frequentam áreas públicas e, com frequência, acabam depositando seus dejetos nesses locais. Vale pena mencionar que esses resíduos acumulados formam substratos propícios para a proliferação de moscas, uma vez que estes insetos são associados a lixo, esterco, carcaças, fezes, entre outros.

\section{Promoção da Saúde no âmbito escolar}

Para o Ministério da Saúde, a escola representa um ambiente educacional e social propício para se trabalhar conhecimentos e mudanças de comportamento (BRASIL, 1997). É importante lembrar que, segundo Rezende (1986), a educação é um instrumento de transformação social, de reformulação de hábitos, aceitação de novos valores e que estimula a criatividade e, segundo Artur da Távola (data), é um processo rico e enriquecedor, pois contém o germe da crítica, reflexão e consciência.

No espaço escolar, as questões sobre saúde ou o saber teórico e prático sobre doenças foi sendo construído de acordo com o cenário ideológico da época e o referencial teórico de cada momento.

Para a Organização Pan-americana de Saúde - OPS (1995):

... a promoção da saúde no âmbito escolar parte de uma visão integral, multidisciplinar do ser humano, que considera as pessoas em seu contexto familiar, comunitário e social. Procura desenvolver conhecimentos, habilidades e destrezas para o autocuidado da saúde e a prevenção das condutas de risco em todas as oportunidades educativas; fomenta uma análise crítica e reflexiva sobre os valores, condutas, condições sociais e estilos de vida, buscando fortalecer tudo aquilo que contribui para melhoria da saúde, da qualidade ambiental e do desenvolvimento humano.

A educação em saúde consiste em proporcionar à população os conhecimentos e as destrezas necessárias para a promoção e proteção de sua saúde individual, da saúde de sua família e de sua comunidade, por meio do desenvolvimento de capacidades e habilidades para que as pessoas participem ativamente na definição de suas 
necessidades e consigam negociar e implantar suas propostas para a obtenção das metas de saúde (CERQUEIRA, 1997).

Dessa forma, a educação em saúde deve estar presente em todas as ações para promover a saúde e prevenir as doenças, facilitando a incorporação de ideias e práticas corretas que passem a fazer parte do cotidiano das pessoas de forma a atender suas reais necessidades. Essa atividade pode ser desenvolvida em espaços diversos, como escolas, por exemplo, permitindo a expansão e o fortalecimento da saúde da população através de um trabalho coletivo e participativo com toda a comunidade escolar (PELICIONI; PELICIONI, 2007).

\section{Educação Ambiental no âmbito escolar}

Já a educação ambiental, para Ab'saber (1996), é o conhecimento da estrutura, da composição e da funcionalidade da natureza e das interferências do homem nos componentes, estrutura e função da natureza. E, para Dias (2000) é um processo onde as pessoas apreendem como funciona o ambiente, como dependemos dele, como o afetamos e como promovemos a sua sustentabilidade.

Considerando a importância do tema, Jacobi (2003) afirma que a educação ambiental assume cada vez mais uma função transformadora, na qual a corresponsabilização dos indivíduos torna-se um objetivo essencial para promover um desenvolvimento sustentável. Entende-se, portanto, que a educação ambiental é condição necessária para modificar um quadro de crescente degradação socioambiental. Vasconcellos (1997), também, ressalta que as práticas educativas voltadas à Educação Ambiental deveriam abordar uma reflexão sobre as relações dos seres entre si, do ser humano com ele mesmo e do ser humano com seus semelhantes.

A educação ambiental é atravessada por vários campos de conhecimento, deve respeitar a diversidade cultural, social e biológica, sendo a escola uma instituição dinâmica que deve compreender e articular os processos cognitivos com os contextos da vida.

Assim, as escolas são espaços privilegiados na implementação de atividades que propiciem essa reflexão, com atividades de sala de aula e atividades de campo, com ações orientadas em projetos e em processos de participação que levem à autoconfiança, 
à atitudes positivas e ao comprometimento pessoal, com a proteção ambiental implementados de modo interdisciplinar (DIAS, 1992).

Diante disso, para despertar nos alunos uma conscientização ambiental, tornase necessário o desenvolvimento de projetos e atividades que propiciem a oportunidade de vivenciar e colaborar para a produção de um meio ambiente mais limpo e preservado, aliando teoria e prática.

O objetivo das atividades foi de sensibilização da comunidade escolar com relação aos vetores de doenças, para fomentar iniciativas que transcendam aquele ambiente, atingindo tanto o bairro no qual a escola está inserida, como outras comunidades, com informações e práticas aos alunos que frequentam as escolas.

\section{PROCEDIMENTOS METODOLÓGICOS}

O presente trabalho foi realizado no município de Teodoro Sampaio, SP, localizado a $22^{\circ} 53^{\prime} 25^{\prime \prime} \mathrm{S}$ e a $52^{\circ} 16^{\prime} 75^{\prime \prime} \mathrm{W}$, distante $112 \mathrm{~km}$ de Presidente Prudente e 672 km da capital São Paulo. O município encontra-se no extremo oeste do estado de São Paulo (Figura 1).

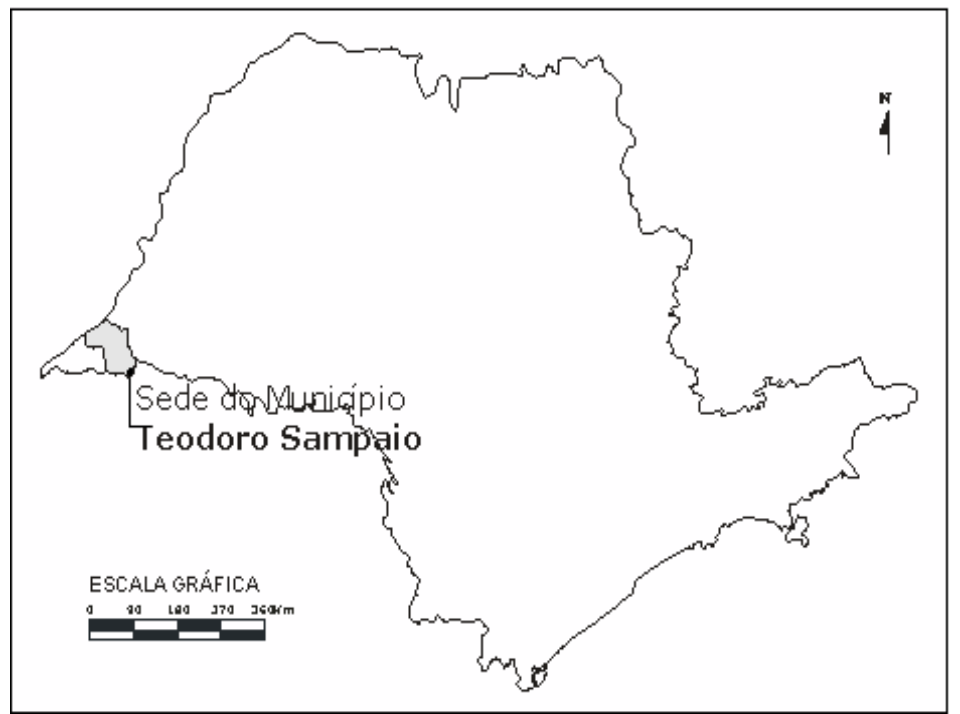

Figura 1. Localização de Teodoro Sampaio no Estado de São Paulo Fonte: Viana e Amorin (2008). 
A EMEF Pedro Caminoto possui 240 alunos, $5^{\underline{a}}$ a $8^{\underline{a}}$ series, com nove classes. A atividade programada para a Semana do Meio ambiente, com os alunos dessa escola, dos períodos da manhã e da tarde, foi a confecção de um desenho sob o tema "A saúde ambiental começa no meu quintal". Os desenhos seriam avaliados pelos organizadores da programação, e os três melhores trabalhos seriam premiados com brindes doados pelos comerciantes do município. Além disso, todos os desenhos elaborados pelos alunos seriam expostos em uma sala, juntamente com as fotografias dos lixões de Tupã (antes e após sua desativação) e do Aterro controlado de Teodoro Sampaio. Ainda, programou-se apresentação de duas palestras, intituladas "Meio ambiente: Vetores de doenças como indicadores de qualidade ambiental" e " A importância das árvores para as aves", para os alunos de cada período, ministrada pela doutorada Leonice Seolin Dias.

\section{RESULTADOS E DISCUSSÃo}

Foram elaborados pelos alunos 200 desenhos, em salas de aulas de Educação Artística, sob a orientação dos professores, duas semanas antes do dia programado para a realização das atividades comemorativas à Semana do Meio ambiente (05 de setembro de 2012).

No dia estabelecido para a exposição, pela manhã, os desenhos foram expostos em uma sala intitulada "Meio ambiente e paisagem", juntamente com algumas fotografias dos lixões de Tupã e Teodoro Sampaio (Figura 2).

Após a preparação da sala com os desenhos e as fotos, no pátio da escola os alunos do período da manhã participaram das duas palestras programadas, com discussão dos temas (Figura 3).

O mesmo procedimento ocorreu com os alunos do período da tarde.

A entrega de um certificado e dos brindes para os alunos que tiveram seus desenhos escolhidos como sendo os mais criativos, ocorreu no encerramento da programação, juntamente com a direção de cada escola (Figura 4). 

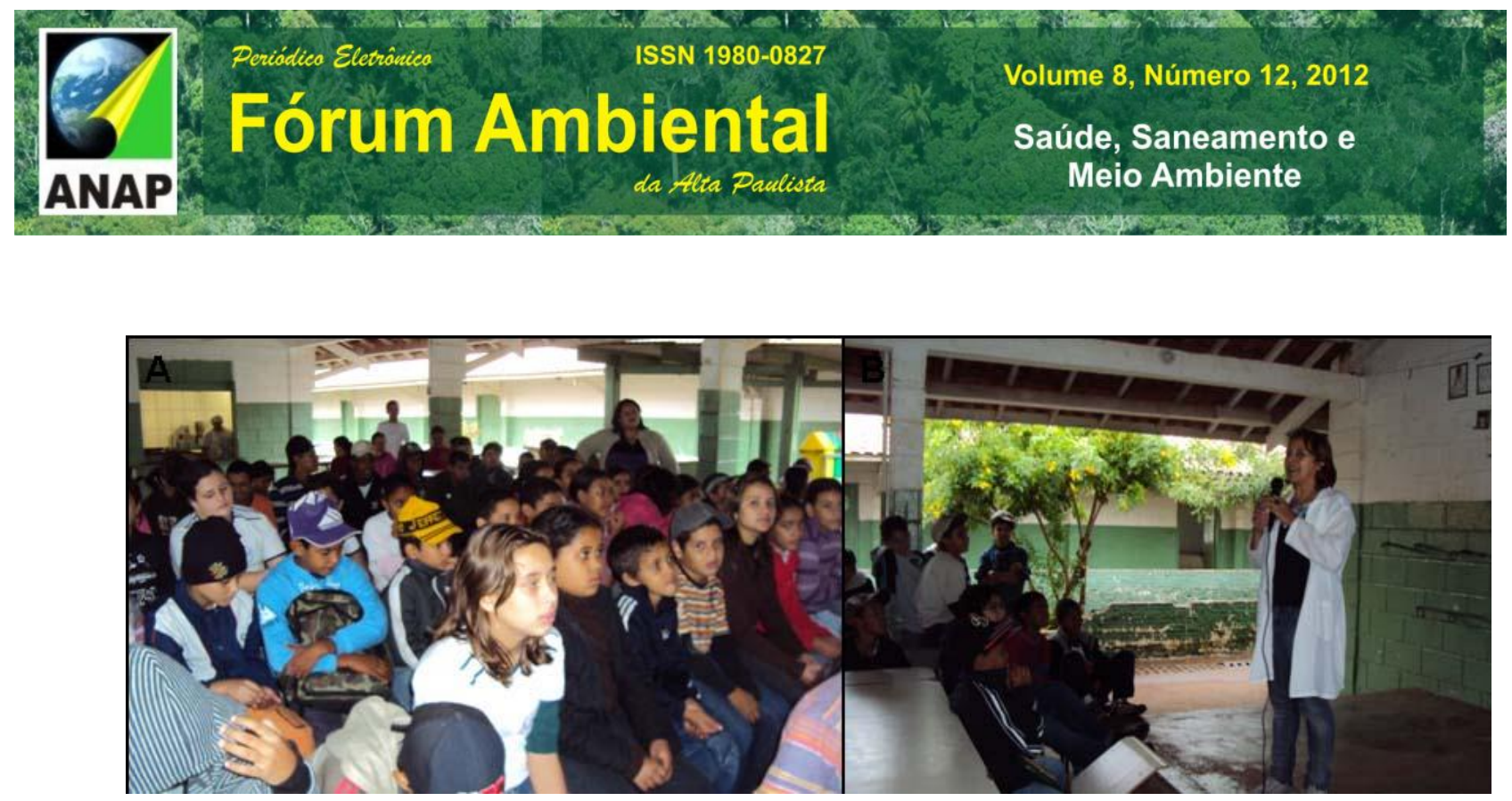

Figura 2. Apresentação das palestras: A) Os alunos, no pátio da escola, assistindo as palestras "Meio ambiente: vetores de doenças como indicadores de qualidade ambiental" e "A importância das árvores para as aves"; B) Momento de transmissão do conteúdo das palestras pela doutoranda Leonice Seolin Dias. Fonte: SEOLIN DIAS (jun. 2012).

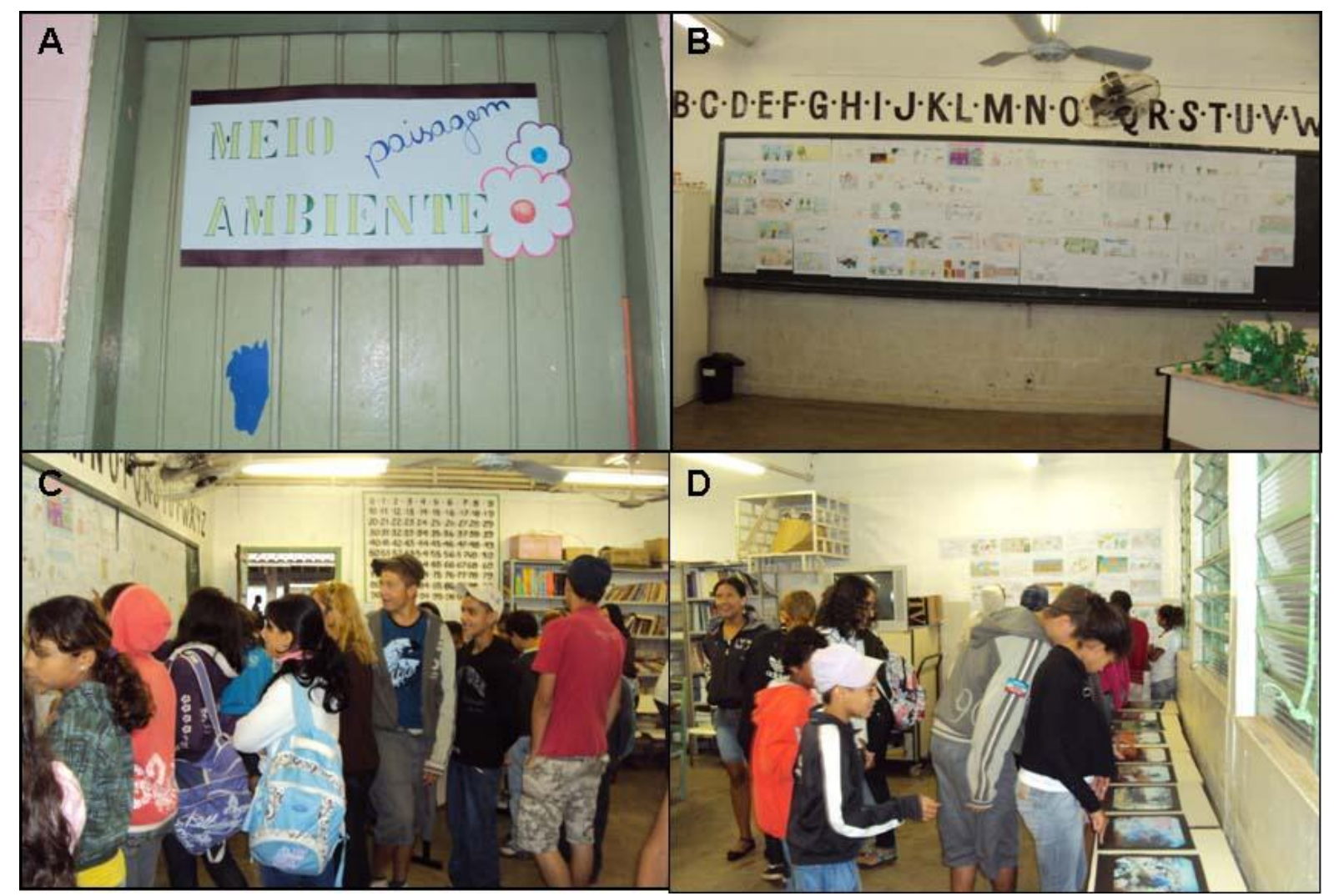

Figura 3. Exposição dos desenhos e das fotos: A) O título para a sala de exposição; B) parte dos desenhos confeccionados pelos alunos; C e B) Os alunos analisando e discutindo o material exposto. Fonte: SEOLIN DIAS (2012). 


\section{Periódica Eletránica

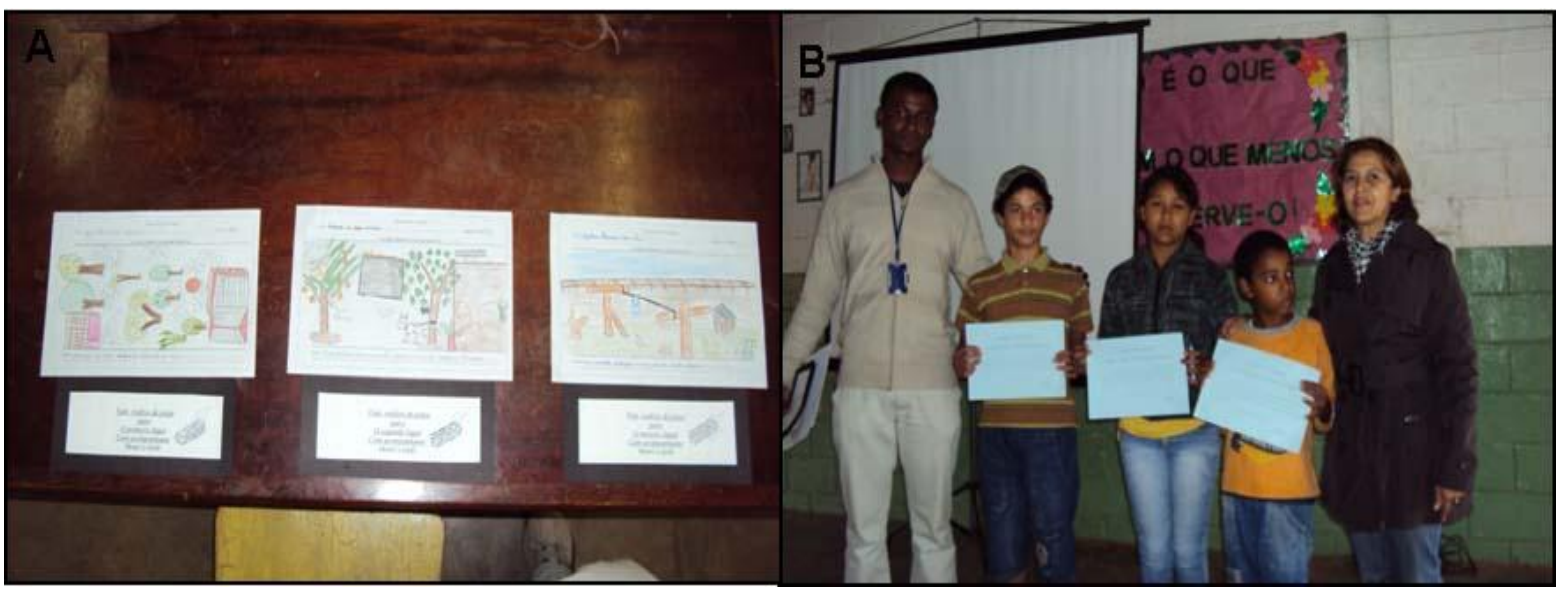

Figura 4. Momento da premiação dos trabalhos selecionados: A) Em ordem de classificação, os três desenhos premiados; B) Jovelino José da Silva Junior (coordenador da escola), os três alunos que tiveram os trabalhos escolhidos e Leonice Seolin Dias, doutoranda da UNESP. Fonte: SEOLIN DIAS (jun. 2012).

É importante mencionar que a nossa intenção com esse trabalho não foi educar os alunos das escolas participantes das atividades, mas sensibilizá-los, uma vez que aprendemos a valorizar cada ato realizado.

Ressaltamos que nos sentimos importantes quando percebemos os desejos e os esforços da equipe idealizadora da programação e, também, dos professores e colaboradores das escolas prestando auxílio com o que fosse necessário para a realização das atividades propostas.

\section{CONSIDERAÇÕES FINAIS}

O trabalho de sensibilização dos estudantes procurou buscar alternativas que promovessem uma contínua reflexão voltada à mudança de hábitos e que tratasse da Educação Ambiental além do sugerido nos livros didáticos, em imagens ilustrativas ou exposições em salas de aulas.

Buscamos desenvolver uma interação que pudesse propiciar um anseio da comunidade escolar em construir um futuro melhor, para se viver em um ambiente equilibrado, em harmonia com o meio, com os outros seres vivos e com nossos semelhantes.

Estamos certos de que a educação é a ferramenta para garantir a continuidade e expansão do conhecimento sobre nós mesmos e do universo em que vivemos. Ela é 


\section{Periádica Eletránica \\ Fórum Ambiental}

da Tlita Paulista
Volume 8, Número 12, 2012

Saúde, Saneamento e

Meio Ambiente

responsável por formar, orientar e conduzir o desenvolvimento das atuais e novas gerações, transmitindo-lhes os conhecimentos adquiridos pela humanidade ao longo de sua existência e clareando os caminhos à frente na construção do futuro.

Sabendo-se que a educação em saúde é uma das melhores formas de se obter a prevenção de várias patologias, a escola, dentro da Educação Ambiental, deve sensibilizar a consciência e também a formação cidadã e participativa dos alunos.

\section{REFERÊNCIAS}

AB'SÁBER, A. N. Amazônia: do discurso à práxis. São Paulo: EDUSP, 1996.

ALMEIDA FILHO N, ROUQUAYROL, M.Z. Desenhos de pesquisa em Epidemiologia. In: Epidemiologia \& Saúde. Rio de Janeiro: Medsi; p. 169-190, 2002.

BRASIL. Ministério da Saúde. Guia de Vigilância Epidemiológica. Brasília: Ministério da Saúde; 2005.

BRASIL. Ministério da Saúde. Criança, adolescente e adulto jovem: documento de referência para o trabalho de prevenção das DST, Aids e drogas. Brasília: Ministério da Saúde; 1997.

CARRERA, M. Insetos de Interesse Médico e Veterinário. Curitiba: Editora da UFPR,1991, 250 p.

CERQUEIRA, M T. Promoción de la salud y educación para la salud: retos y perspectivas. In: ORGANIZACIÓN MUNDIAL DE LA SALUD. La promoción de la salud y la educación para la salud en América Latina: un análisis sectorial. Genebra: Editorial de La Universidad de Puerto Rico, 1997. p. 7-48.

COMIS, R.; VIEIRA, D.; PICAVÊA, J. P.; QUEROL, E.; QUEROL.; M. V. M. Atividade de Educação ambiental visando a melhoria da qualidade de vida da população do CEANE, em Uruguaiana, RS - prevenção das zoonoses e doenças transmitidas pela água não tratada. Educação ambiental em ação, n. 11, 2005. (Revista On-line).

DIAS, G. F. Educação ambiental: princípios e práticas. 6.ed. São Paulo: Gaia, 2000.

DIAS, G. F. Educação Ambiental: princípios e práticas. São Paulo, Gaia,1992.

FORATTINI, O. P. Ecologia, epidemiologia e sociedade. São Paulo: Artes Médicas, 2004.

GREENBERG, B. Flies and diseases. Ecology, classification and biotic association. Princeton: Princeton University, 1971. 856p. 
JACOBI, P. Educação Ambiental, cidadania e sustentabilidade. Cadernos de Pesquisa, São Paulo, n. 118, p. 189-205, 2003.

LIMA, A. M. A. et al. Percepção sobre o conhecimento e profilaxia das zoonoses e posse responsável em pais de alunos do pré-escolar de escolas situadas na comunidade localizada no bairro de Dois Irmãos na cidade do Recife (PE). Ciênc. saúde coletiva, v. 15 supl.1, 2010.

MIGUEL, O. A vigilância sanitária e o controle das principais zoonoses, Epistéme, v. 1, n.1, p.141-155, 1996.

OPS. ORGANIZAÇÃO PANAMERICANA DE SAÚDE. Educación para la salud: un enfoque integral. Washington: OPS, 1995. (Série HSS/SILOS, n. 37).

PELICIONI, M. C. F.; PELICIONI, A. F. Educação e promoção da saúde: uma retrospectiva histórica. O mundo da saúde, São Paulo, v. 31, n. 3, p. 320-328, 2007.

SILVA, J. C. R. Zoonoses e doenças emergentes transmitidas por animais silvestres (2008). Disponível em: <http://www.portaleducacao.com.br/veterinaria/artigos/2463/zoonoses-e-doencasemergentes-transmitidas-por-animais-silvestres\#ixzz27TsllcHQ.> Acesso em: 28 set. 2012.

VASCONCELLOS, H. S. R. A pesquisa-ação em projetos de Educação Ambiental. In: PEDRINI, A. G. (org). Educação Ambiental: reflexões e práticas contemporâneas. Petrópolis: Vozes, 1997.

ZUMPT, F. Myiasis in man and animals in the Old World. London, Butterworths, 1965. $267 \mathrm{p}$. 